\title{
The Design of Wireless Communication Function of Traction Substation Electrical Signal Monitoring Device
}

\author{
Chun Huan Song \\ School of Electronic Information Engineering, Xi'an Technological \\ University, china \\ faysch@163.com
}

\begin{abstract}
In this paper, according to the characteristics of the electrified railway electrical signal, wireless communication functions of signal acquisition system was designed. Acquisition system through two levels of transformer to realize signal conversion, finished signal filtering by using fourth-order filter; Acquisition control circuit adopted double CPU structure, ADSP to perform high-speed data acquisition, signal processing and analysis, signal compression and encryption, $M C 551$ was used to control the man-machine interface and wireless communication interface, between the two CPU communication through dual port RAM to implement; Based on GSM technology and design of the wireless communication circuit.
\end{abstract}

Keywords: Electrified Railway, Traction Substation, Electrical Signal Monitoring Device, Wireless Communication Function

\section{Introduction}

With the continuous development of transportation industry, railway enterprise became to the focus of the transportation enterprise, and the emergence of electrification railway also made important contribution to the development of railway. Electrified railway was the railway electric traction, was constitute by electric locomotive and power supply system, the influence of electrified railway on power grid has been the general concern. Electrified railway into power grid harmonic current, negative sequence influence on generator, voltage fluctuation caused by impact load, electric iron harmonic and negative sequence influence on relay protection, the influence of harmonic power to electric power electric iron, electric iron harmonic power influence on electric energy metering and had a great impact on electrified railway [1-3]. In order to adapt to the continuous development of China's high speed railway electrification. In this paper, the design of a wireless network function Electrical signal acquisition system, which was used as a small independent power monitoring equipment, also was used as a signal acquisition system, the high voltage signal into digital signal, and send the data to the master server through wireless communication network, users can access the server through the network, the effective operations of control circuit.

\section{Electrical Signal Acquisition System Design Improvements}

Electrical signal sampling used ADSP technology for processing of signal, the user through the software type or the drop-down menu to select parameters of raw data, used to display or sent to the external processing units (include the device such as microcomputer) [4-5]. As shown in figure 1. The overall structure of the system, as shown in the process of operation, according to the level of voltage and current, the user choose high voltage transformer, reduced the signal amplitude; Through the signal conversion module, converts the signal into AD chip was collected by weak current signal, and signal 
disposal (filter), sampling control circuit output signal conversion module, with the method of FFT, the realization of digital filtering, parameter calculation, and stored in the dual port RAM, auxiliary CPU choose display and sent [6].

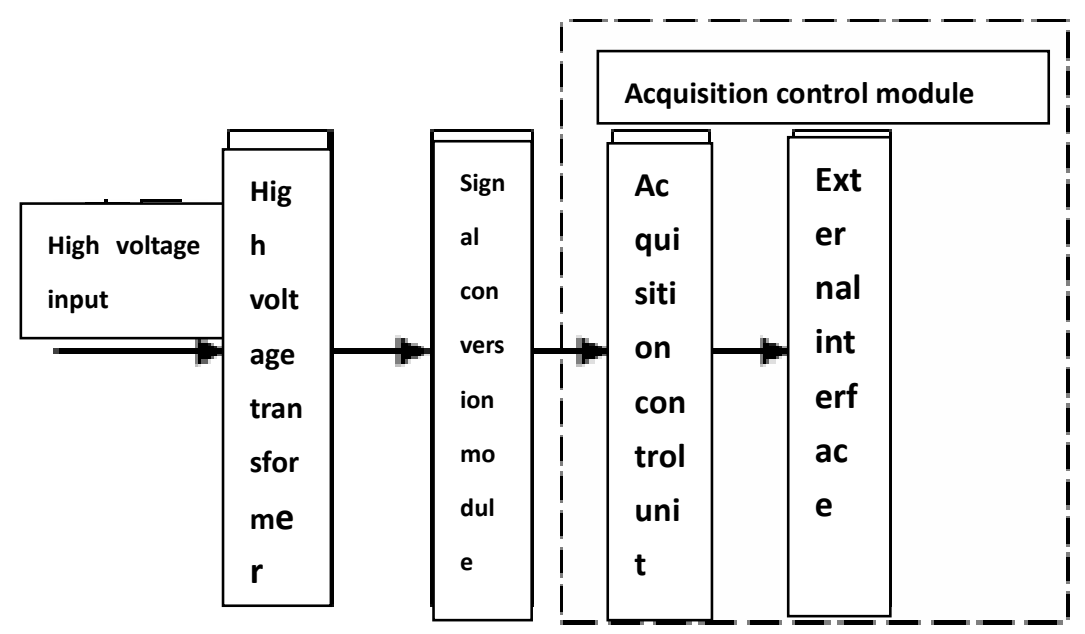

Figure 1. Overall Structure

\subsection{The Design of the Signal Conversion Module}

Signal transformation part is mainly composed of voltage transformer and its matching circuit. Signal conversion module's function was to convert the input signal features, size, etc., to make it conform to the requirements of the acquisition circuit of signal input [7]. In actual circuit module of the input of Vim is transformer output 100 VA voltage or $5 \mathrm{~A}$ ac current, choose SPT204A (rated current for $2 \mathrm{~mA}$ ) and SCT254A current transformer voltage transformer isolation device for electric parameters, and through its combination circuit to get high precision, good linearity output $5 \mathrm{v}$ ac voltage. Concrete as shown in figure 2. As shown in figure 2, the H1 was SPT204A, it is milliamperes precision voltage transformer, current limiting resistor $\mathrm{R} "=100 / 2 \Omega=50 \mathrm{k}, \mathrm{R} \Omega$ choose $2.4 \mathrm{k} \Omega$.

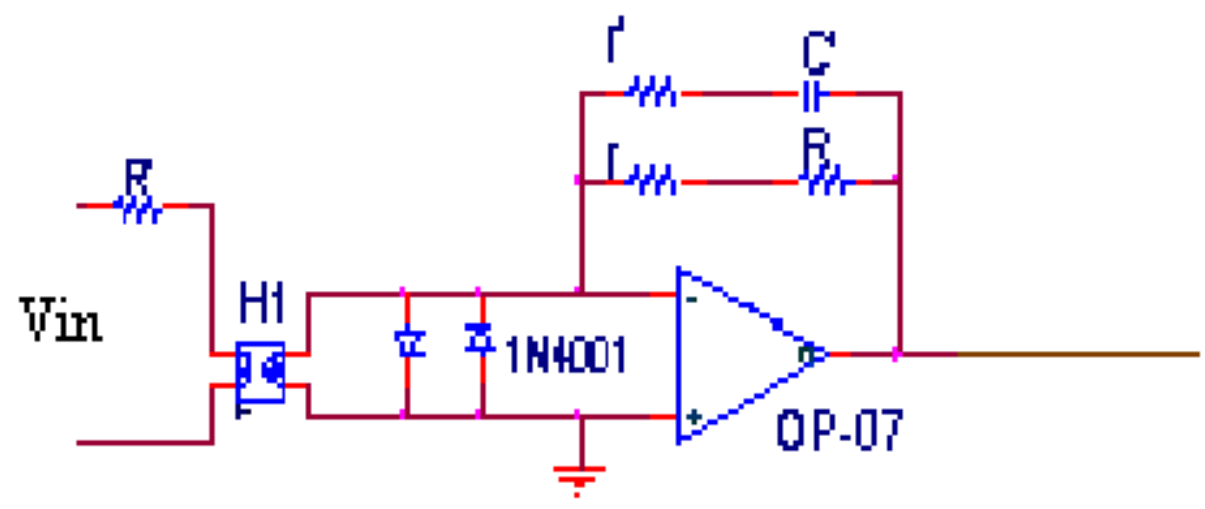

Figure 2. Signal Conversion Circuit Diagram

\subsection{The Filter Design}

Power filter was composed of capacitance and inductance and resistance of filter circuit. Specific frequency of the filter to the power cord or the point that the frequency of frequency effectively filter out, got a specific frequency power signal, after a particular 
frequency or eliminate power signal [8]. Electric parameters of four order harmonic accurately measuring 20 times, in the setting of each phase in each cycle collected 256 points, then collected 51200 points per second. According to the Nyquist sampling theorem, the sampling frequency was twice the maximum frequency of the signal, the filter filted out the frequency of $51.2 \mathrm{kHz}$ signal, but in fact there was no this kind of situation, on line did not consider this aspect of the problem. Concrete design was shown in figure 3.

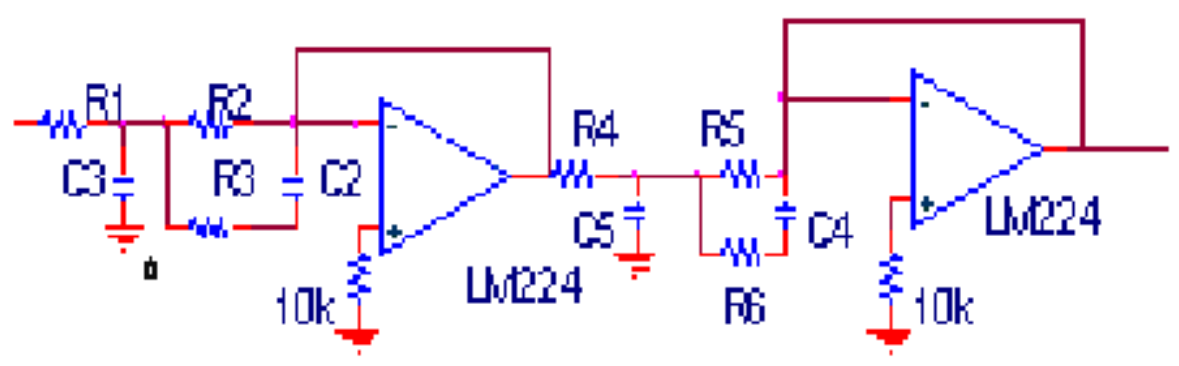

Figure 3. Four Order Filter Design

\subsection{Acquisition Control Circuit Module Design}

Circuit module accomplish the adaptive variable precision signal acquisition, signal processing and analysis, digital signal transmission functions [9-10]. Adopts double CPU structure and CPLD technology and enhance the flexibility and expansibility of the system. Used photoelectric isolation suppress interference. Circuit could be divided into two control circuit, on the one hand, predominantly AD SP CPU circuit, through the selection of CPID multiplex control circuit and gain amplification circuit, adaptive precision of multi-channel signal acquisition, signal acquisition by FFT digital filter for filtering, used FFT algorithm, calculate the parameters such as harmonic, power signal, coexistence of dual port RAM. Another aspect was M CS51 auxiliary CPU auxiliary control circuit, its main function was through the RAM and ADSP communication, according to user's requirements, the collection and calculation of the proceeds of the signal and the parameters were sent to the computer and other external equipment, auxiliary circuit including power monitoring, clock, calendar, communication interface and the external interface chip, such as man-machine interface, through the CPID technology extension of wireless communication interface.

Gain amplifier circuit designed software control principle was adopted to design and its principle diagram as shown in figure 4. Mainly through cooperate with ADSP, automatic adjusting the amplifier gain. In this circuit, a nonvolatile digital potentiometer DS1805, block was mainly composed of EEPROM, control circuit and a potentiometer, $\mathrm{W}$ for potentiometer pins. ADSP to DS1805 input digital, in order to adjust the resistance of between $\mathrm{W}$ and $\mathrm{L}$, adjustable resistance and $\mathrm{Rl}$ series, the formation of resistance. 


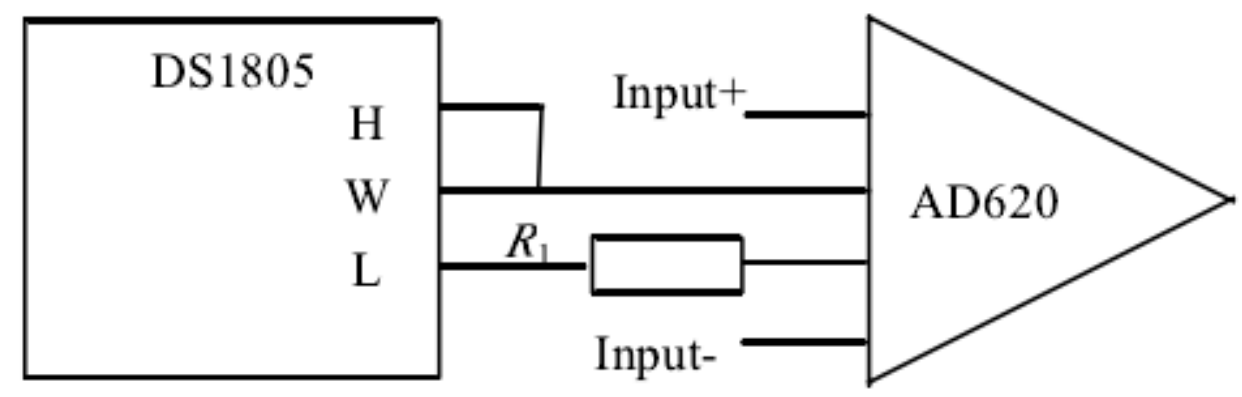

Figure 4. Gain Amplifier Circuit Design Principle

\section{The Implementation of the GSM SMS Communication System}

\subsection{Based on the Technology of GSM Short Message Network Generalization of Structure Design}

Global System for Mobile communications (Global System for Mobile Communication, GSM) was the air interface USES time division multiple access technology, the most widely used Mobile phone standard, as well as the most mature of Mobile Communication System, the most perfect, the most widely used of a System [11-12]. At present our country already all used GSM cellular mobile communication network, the main way of mobile communication was in China. The entire network was mainly composed of terminal detection equipment, terminal equipment communication module, GSM communication network, communication manager, management of workstation [13].

The question of using network based on terminal and server communication wireless network (Network equipment), was used to the remote computer Internet network and server connection, as well as for mobile phones and other mobile devices connected to the server of the wireless network [14]. Network equipment was through the terminal communication equipment, GSM network, data communication equipment and the management server. Two communication module completed the information of data compression and decompression, data validation, data signal sending and receiving functions, such as network equipment communication with China mobile GSM communication network, possesses the advantages of reliable, maintenance free. Communications manager and the function of the terminal communication module.

\subsection{The Realization of the Network Structure Design of GSM Short Message Technology}

Most of the communication module was adopted Siemens run TC 35 modules. This module had A baseband processor, GSM rf part, power supply A - SIC (Application Specific integrated Circuit), Flash four big modules [14]. GSM baseband processor was the core of the whole module, it consisted a C166CPU and a DSP processor core modules in a variety of signal transmission, transformation, and amplification process [14]. GSM rf part was a single-chip transceivers, whic was created by a heterodyne receiver, up-conversion transmitter, a radio frequency modulation loop phase lock loop (PLL) and a fully integrated intermediate frequency synthesizer four function blocks, together complete the rf signal processing such as receiving and sending. TC35 module supports data, voice, facsimile and short message communication, had a standard RS232 interface, whic connected to the computer or single chip microcomputer was used. 


\subsubsection{GSM SMS Communication Module Circuit Design}

GSM SMS communication module and terminal station of GSM communication module was using the same principle to carry on the design, the difference was the terminal module through the MCS51 control, and communication through the PC COM port. Terminal equipment of the communication module circuit diagram as shown in figure 5. MCS51 used through dual port RAM and DSP for data exchange, through ADSP processing information for data compression, and then through TC35 sent to the GSM network. In the process of data reception, MC 551 mainly used to extract the data, checked and judged command, sent commands to the ADSP, etc. Done in 8250 function modules of CPID by the MCS51 and TC35 module exchange data, realized the combination of hardware, and data flow controled.

TC 35 connects a subscriber identity module (SM), a SIM card contained all the user information, and the legitimacy of the GSM system automatically identifed the user, only the system only after approval by providing service for the mobile users. TC 35 used external SIM card, ZIF had 6 pin connector as SIM card interface, had six SIM card pin, respectively, and their corresponding [15].

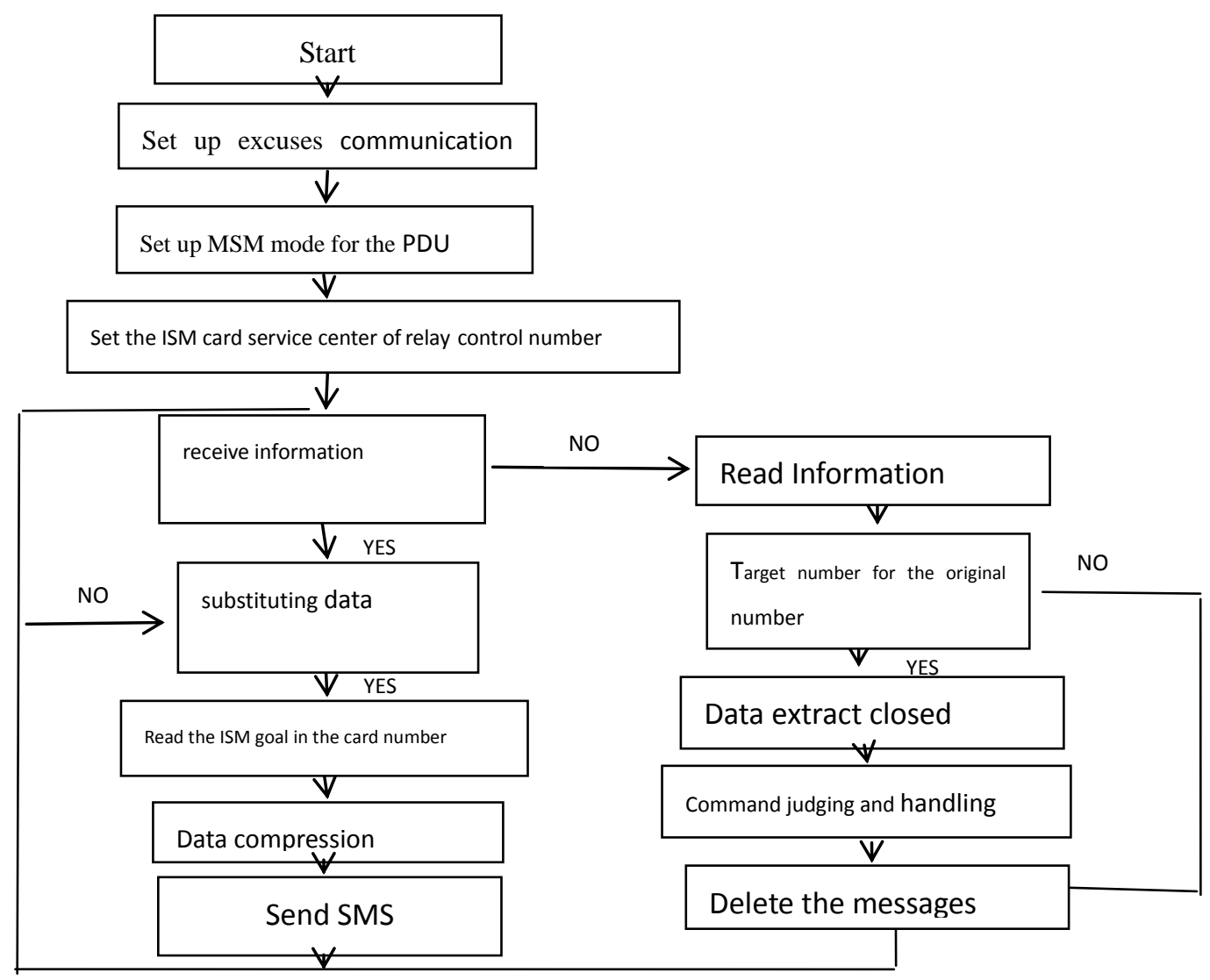

\subsubsection{System Equipment Configuration and System Functional Components}

Local monitored hardware configurated by local monitoring machine, printer, mimic panel, optical transceiver, OPH, power cabinet and protection measurement and control device. According to the characteristics of the traction substation main wiring and power supply mode, protected measurement and controlled device through the main transformer and main protection measurement and control device, the backup protected on the $110 \mathrm{kV}$ side of the transformer measurement device, the backup protected on the $27.5 \mathrm{kV}$ side of 
the transformer measurement device, the switch device, capacitance protection device and the configurations of feeder protection device.

Monitoring data processing in the component includes cumulatived active reactive power of each route; The limit of detection (the main transformer overload, main transformer overheating, busbar voltage was too high or too low, PT disconnection, straight loss pressure); Grounding detection. Components was controlled by the distance or local monitoring machine or emergency line selection control. Each in the protection of transformer protection unit was set separately respectively as main protection of transformer differential protection. Feeder was equipped with the direction of distance protection as the main protection, large current instantaneous fault protection, current overload protection as auxiliary protection to overcome direction protection dead zone ${ }^{[15]}$. Other components of the control protection was also depending on the voltage protection Settings accordingly.

\subsubsection{Communication Software Settings}

In principle, the data communication module and terminal communication module of communication software was basically the same, basic terminal communication module of the software designed. Software function mainly includeed the data compression and decompression, sent and received the inspection data, commanded recognition, etc. Sent and received data through the GSM module to send V25 standard AT commands to complete [16]. Saw the specific process as shown in figure 4. Mainly used the data compression and decompression, data was sent and received and inspected, and identification of command functions such as signal conduction and to send, so as to achieve accurate transmission of target information.Communication software Settings to ensure the stability of circuit operation, the signal was normal, reduced unnecessary failure in operation of the circuit.

\section{The Design of the Traction Transformer Module}

Traction transformer was the heart of the high-speed railway traction power supply system, mainly to the power system of single-phase ac three-phase alternating current into the right through the feeder access catenary provides energy for the train. China's high speed railway traction power supply system with autotransformer (AT) power supply mode, its main transformer common connection mode were: (1) single phase V/V connection; (2) three-phase V/V connection; (3) Scott wiring; (4) v/x wiring [17]. Research showed that choosed the AT power supply mode and V/X wiring traction transformer had the rationality. Had been widely used. This system also used V/x wired traction transformer, its circuit principle diagram as shown in figure 6.According to the principle of $\mathrm{V} / \mathrm{x}$ wiring traction transformer design, the design parameters of the system of traction transformer module setted the results were shown in table 1.These results were based on the following formula: pulling the calculation of the main transformer capacity formula: $\mathrm{S}=U_{2 N} I_{\varepsilon}$; Select the maximum capacity of main transformer of traction formula [18]: $S_{\max }=U_{2 N} I_{\varepsilon}$. Max. And drawing of the main transformer capacity for checking school $\mathrm{S}=\mathrm{Smax} / \mathrm{k}$, the $\mathrm{k}$ for load ratio, set it to $175 \%$. S - S calibration= computing capacity of traction transformer $=275 \mathrm{v}$. A. Checked capacity of school $\mathrm{S}=314.3 \mathrm{~V}$.A. Such design ensured more high-speed railway traction power supply system and stable operation, reduced the occurrence of signal failure. 
Table 1. Parameters Design for the Traction Transformer Module

\begin{tabular}{cccc}
\hline Name & $\begin{array}{c}\text { Line } \\
\text { capacity } \\
(\text { VA })\end{array}$ & $\begin{array}{c}\text { No-load } \\
\text { transformer ratio } \\
(\mathbf{V} / \mathbf{V})\end{array}$ & $\begin{array}{c}\text { short circuit } \\
\text { impedance } U_{\mathbf{k}} \\
(\%)\end{array}$ \\
\hline $\begin{array}{c}\text { Traction } \\
\text { transformer }\end{array}$ & 315 & $380 / 2 \times 27.5$ & 8.6 \\
\hline
\end{tabular}

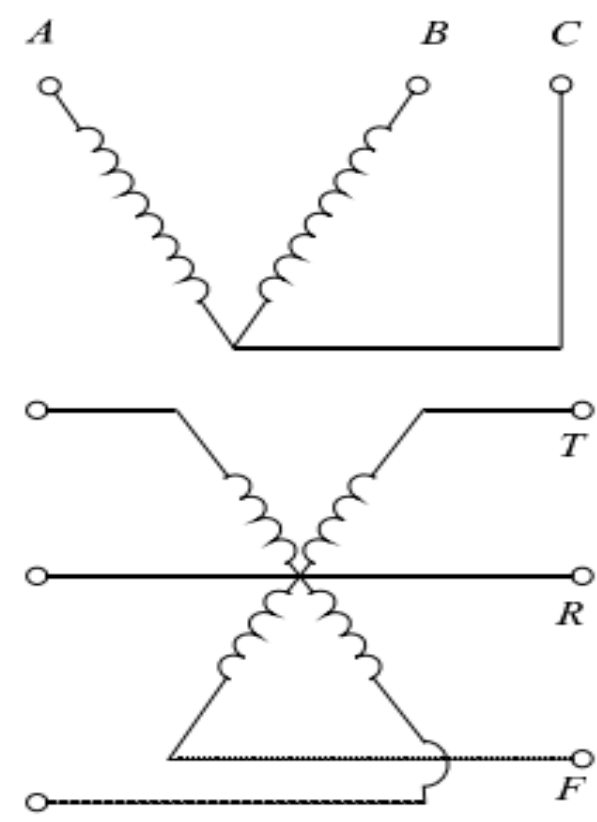

Figure 6. Schematic Diagram of V/X Traction Transformer

\section{Conclusion}

Transmission is a kind of modern technology and equipment of substation, automation and integrated application in the field of computer and communication technology in the substation, whith is the realization of traction substation unattended or less people on duty and reliable technical support. The system improve the function of the traction substation and the management level, the wireless communication function of traction substation electrical signal monitoring system is the inevitable developing trend of domestic traction power supply system.

With the continuous development of communication technology, the wireless communication used in the implementation of traction substation electrical signal monitoring device for better control automation provide reliable signal of electrified railway, well meet the requirements of railway transportation provides a set of reliable traction substation electrical signal monitoring system, also is the inevitable developing trend of electrified railway.

\section{References}

[1] Anonymous, "Research and Markets; Emerging Technologies and Applications of Short-Range Wireless Communications Revealed[J]", Electronics Business Journal, vol. 132, no. 34, (2009), pp. 1254-1260.

[2] Anonymous, "Wireless Communications; Research from B. Vaidya and Co-Authors in the Area of Wireless Communications Published[J]", Electronics Business Journal, vol. 25, no. 34, (2011), pp. 256-263.

[3] C. Mehlführer, J. C. Ikuno and M. Šimko, "The Vienna LTE simulators-Enabling reproducibility in 
wireless communications research[J]", EURASIP Journal on Advances in Signal Processing, vol. 2011, no. 1, (2011), pp. 1-14.

[4] O. Z. Incel, "A survey on multi-channel communication in wireless sensor networks", Computer Networks, vol. 55, no. 13, (2011), pp. 3081-3099.

[5] Anonymous, "Wireless Communications Research from F. Hasegawa and co-authors yields new data on wireless communications[J]", Computers, Networks \& Communications, vol. 36, no. 59, (2011), pp. 244-256.

[6] H. Ishikawa, "Software Defined Radio Technology for Highly Reliable Wireless Communications[J]", Wireless Personal Communications, vol. 64, no. 3, (2012), pp. 461-472.

[7] M. Aguado, E. Jacob and J. Astorga, "The cross layer RMPA handover: a reliable mobility pattern aware handover strategy for broadband wireless communication in a high-speed railway domain[J]", EURASIP Journal on Wireless Communications and Networking, no. 1, (2012), pp. 1-29.

[8] R. Thakker, S. Sarkani and T. Mazzuchi, "A system dynamics approach to demand and allocation of wireless spectrum for mobile communication[J]", Procedia Computer Science, vol. 8, (2012), pp. 18-123.

[9] M. Y. Naderi, H. R. Rabiee and M. Khansari, "Error control for multimedia communications in wireless sensor networks: A comparative performance analysis[J]", Ad Hoc Networks, vol.10, no. 6, (2012), pp. 1028-1042.

[10] M. Z. Farooqui and P. Saengudomlert, "Transmit power reduction through subcarrier selection for MC-CDMA-based indoor optical wireless communications with IM/DD[J]", EURASIP Journal on Wireless Communications and Networking, vol. 2013, no. 1, (2013), pp. 1-14.

[11] V. M. Rohokale, N. R. Prasad and R. Prasad, "Reliable and Secure Cooperative Communication for Wireless Sensor Networks Making Use of Cooperative Jamming with Physical Layer Security[J]", Wireless Personal Communications, vol. 73, no. 3, (2013), pp. 595-610.

[12] J. Jiang, J. D. Li and R. H. Hou, "Network selection policy based on effective capacity in heterogeneous wireless communication systems[J]", Science China Information Sciences, vol. 57, pp. 2, (2014), pp. $1-7$.

[13] Y. Li, J. Wang and Z. He, "Design and imPlementation of integrated dynamic simulation experiment system of high-speed railway traction Power supply system[J]", Power system protection and control, vol. 13, (2014), pp. 123-128.

[14] Z. Wang, W. He and J. Lv, "The research and imPlementation of portahle wireless ECG acquisition device[J]", Measurement Control Technology and Instruments, vol. 36, no. 11, (2010), pp. 95-99.

[15] W. Deng, X. Yang and H. Zhao, "Design and Realization of the comprehensive automation system for the traction substation[J]", JOURNAL OF RAILWAY ENGINEERING SOCIETY, vol. 8, (2006), pp. 93-96.

[16] W. Hu, Z. Zhao and Z. Lu, "Design of Wireless multi-channel surface EMG acquisition system[J]", JOURNAL OF ELECTRONIC MEASUREMENT AND INSTRUMENT, vol. 23, no. 11, (2009), pp. 30-35.

[17] J. Chen, S. Wang, “APPlication of Intelligent Anti-miisoPeration System in Traction Substation of Passenger Dedicated Line[J]", RAILWAY STANDARD DESIGN,, vol. 58, no. 5, (2014), pp. 121-123.

[18] X. Li, K. Zhou and L. Wan, "DeveloPment of cable termination PD condition monitoring device based on TEV method[J]", Power System Protection and Control, vol. 41, no. 12, (2013), pp. 98-103.

\section{Authors}

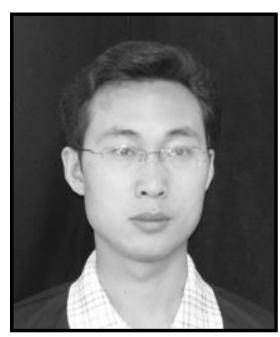

Chun Huan Song, he is presently working as a lecturer at School of Electronic Information Engineering, $\mathrm{Xi}$ ' an Technological University.His research interests are Automatic Control Technique and Digital Signal Processing. 